\title{
Cyclogenesis in the Denmark Strait Overflow Plume
}

\author{
Johann H. Jungclaus, Janko Hauser, and Rolf H. Käse \\ Institut für Meereskunde an der Universität Kiel, Kiel, Germany
}

(Manuscript received 16 February 2000, in final form 30 March 2001)

\begin{abstract}
A densely spaced hydrographic survey of the northern Irminger Basin together with satellite-tracked nearsurface drifters confirm the intense mesoscale variability within and above the Denmark Strait overflow. In particular, the drifters show distinct cyclonic vortices over the downslope edge of the outflow plume. Growing perturbations such as these can be attributed to the baroclinic instability of a density current. A primitive equation model with periodic boundaries is used to simulate the destabilization of an idealized dense filament on a continental slope that resembles the northeastern Irminger Basin. Unstable waves evolve rapidly if the initial temperature profile is perturbed with a sinusoidal anomaly that exceeds a certain cutoff wavelength. As the waves grow to large amplitudes isolated eddies of both signs develop. Anticyclones form initially within the dense filament and are rich in overflow water. In contrast, cyclones form initially with their center in the ambient water but wrap outflow water around their center, thus containing a mixture of both water types. The nonlinear advection of waters that were originally located within the front between both water masses contributes most significantly to the stronger intensification of the cyclones in comparison with anticyclones. The frontal waters carry positive relative vorticity into the center of the cyclone. The process bears therefore some resemblance to atmospheric frontal cyclogenesis. After saturation there is a bottom jet of overflow water that is confined by counterrotating eddies: anticyclones upslope and cyclones downslope of the overflow core. The parameter dependence of the maximum growth rate is studied, and the implications of eddy-induced mixing for the water mass modification is discussed.
\end{abstract}

\section{Introduction}

An important portion of North Atlantic Deep Water (NADW) is formed north of the Greenland-Scotland ridge and finds its way into the open ocean through narrow passages, such as the Faroe-Bank Channel and the Denmark Strait. Downstream of the sill the dense water plume is released onto the continental slope and settles on the bottom in the form of a dense gravity current. The dense bottom flow entrains a considerable amount of ambient water during the descending phase where it is strongly accelerated. The dynamics of such a flow, simplified as a single layer of dense water underlying an upper layer at rest, has been studied with streamtube models by Smith (1975), Killworth (1977), and Price and Baringer (1994). This type of model assumes that the flow is confined to a tube and the predictive equations for temperature, salinity, and momentum are averaged over the cross-sectional area. Jungclaus and Backhaus (1994) developed a horizontally two-dimensional reduced-gravity model that was able to simulate the transient spreading of dense water flow

Corresponding author address: Johann Jungclaus, Max-PlanckInstitut für Meteorologie, Bundesstrasse 55, 20146 Hamburg, Germany.

E-mail: jungclaus@dkrz.de on arbitrary topography and applied it to the Denmark Strait overflow.

The aforementioned models were able to simulate the observed pathway and water mass modifications in the overflow and shed light on the role of bottom friction and the effect of entrainment. However, owing to their simplified physics, the models fell short in reproducing one of the most striking features of overflow observations, the pronounced temporal variability with a timescale of a few days. Cooper (1955) found that the cold overflow water was often contained in huge "boluses" that moved along the slope. The attempt to directly measure the overflow with a current meter array by Worthington (1969) was overshadowed by a loss of nearly all instruments due to the intensity of the bottom currents. The analysis of one of the remaining current meters revealed a highly variable overflow with a period of a few days and peak currents of about $1.5 \mathrm{~m} \mathrm{~s}^{-1}$.

Another aspect of mesoscale variability comes from surface or near-surface observations. Bruce (1995), using satellite IR imagery, detected numerous cyclonic eddies traveling along the continental slope with a typical propagation speed of $27 \mathrm{~cm} \mathrm{~s}^{-1}$ and a diameter of 20-40 km. The existence of cyclonic eddies was confirmed by Krauss (1996) analyzing the trajectories of satellite-tracked buoys (at 100-m depth). Krauss calculated that these eddies had an inner core in solid body 
rotation of $20-30 \mathrm{~km}$ and a total diameter of $60-100$ $\mathrm{km}$. Bruce (1995) suggested that the cold eddies in the IR imagery are a surface signature of propagating cyclonic vortices on the continental slope. The formation mechanism is then the vortex stretching associated with the sinking overflow water. Following this idea Spall and Price (1998) developed the "PV Outflow Hypothesis," in which they explain the mesoscale variability in terms of potential vorticity conservation in a threelayer flow. According to their theory, the cyclones are formed by the stretching of the high potential vorticity column that flows through Denmark Strait. The outflow is assumed to consist of a relatively thin cold and saline layer of Norwegian Sea Deep Water (NSDW) and an intermediate level of fresher Arctic Intermediate Water (AIW). Whereas the dense NSDW layer descends the bottom slope nearly unmodified, the midlevel waters are stretched by more than $100 \%$, which would provide the relative vorticity necessary to produce the observed cyclones. Spall and Price (1998) stress that their mechanism explains the vortices that occur at the upslope side of the overflow plume.

Earlier work on the stability of coupled density fronts (Griffiths et al. 1982) suggested that dense water veins might be inherently unstable. Griffiths et al. (1982) studied the dynamics of a reduced gravity single-layer fluid underlying an upper layer at rest theoretically and in the laboratory. Nearly all currents were unstable and the instability was associated with the coupling of the lateral boundary streamlines. Laboratory experiments corroborated the theoretical findings for those cases, where the density current was sufficiently narrow. For currents much wider than the Rossby radius, however, the instability developed substantially differently and Griffiths et al. speculated that it was essential baroclinic. Following this idea, Swaters (1991) developed a theoretical model with two active layers and presented a linear stability analysis for a dense bottom vein on a sloping continental shelf. The instability was shown to be baroclinic in the sense that mean potential energy is released by the downslope slumping of the perturbed density front on the downslope edge of the dense filament. The density front is strongly coupled to the upper layer through the mechanism of vortex stretching and compression. The perturbations are manifested in the form of amplifying anticyclones on the downslope density front and in the ambient slope water, they appear as growing topographic Rossby waves. In the two-layer model the interface between the density current and the ambient water slopes more steeply on the downslope edge so that the necessary condition for instability is more likely fulfilled on the offshore side.

In their discussion of possible explanations for the mesoscale variability in the overflow Spall and Price (1998) rejected the Swaters (1991) theory for three reasons: 1) The sense of the deep circulation would be anticyclonic around maxima in plume thickness in contrast to the Spall and Price (1998) model results [but in agreement with Krauss and Käse's (1998) hydrographic data]; 2) the linear instability theory would predict an equal number of cyclones and anticyclones, whereas the surface observations show predominantly cyclonic vortices; and 3) Swaters' instabilities would manifest themselves mainly over the downslope side of the plume whereas Bruce's (1995) observations favored eddies on the inshore side (but see below).

We shall demonstrate here that the dominance of cyclonic vortices in our new near-surface observations can be explained by a baroclinic instability and subsequent nonlinear eddy evolution. In this study we therefore wish to present a link between the two-layer theoretical instability analysis by Swaters (1991) and Karsten et al. (1995) on the one hand and the fully three-dimensional, nonlinear simulations performed with general circulation models by Jiang and Garwood (1996) and Krauss and Käse (1998). In contrast to the latter we explicitly exclude the sinking of the dense water plume from the shelf edge (which can indeed be an additional source of vortex stretching and may account for some of the eddy activity seen on the upslope edge of the dense plume) but concentrate on the destabilization of a density current that flows basically along the topography. Using a periodic domain and a prescribed Gaussianshaped dense filament on an idealized continental shelf we wish to compare the results for a Rossby number regime of $O(1)$ to the asymptotic solutions given in Swaters (1991) and to some extent to Griffiths et al. (1982). It should be noted here that the first interpretation of the mesoscale variability in terms of baroclinic instability was due to Peter Smith (1976) for the Denmark Strait overflow. He applied a quasigeostrophic channel model to the Denmark Strait. However, as was shown by Swaters (1991), this type of model (where the flow is bounded by lateral walls) is not directly applicable to the dense filament problem where the edges of the flow intersect the bottom.

\section{Observations from the Irminger Basin}

During cruise 222 of R.V. Poseidon in August 1996, when the hydrographic data used by Krauss and Käse (1998) were obtained, a number of satellite-tracked buoys drogued at 100-m depth were also deployed. The trajectories of these drifters complement those from an earlier campaign (Krauss 1996). A compilation of all tracer trajectories is given in Fig. 1a where we also redisplay the dynamic topography $100 / 1000 \mathrm{dbar}$ from Krauss and Käse. The dynamic topography was obtained from the densely spaced hydrographic survey by objective analysis. The dynamic topography is, of course, not synoptic and the mesoscale circulation inferred from it is not compatible with the drifter motion. However, the drifter trajectories confirm clearly that most of the mesoscale variability appears above the cold overflow water. In particular, several trajectories were captured in propagating eddies. Two drifters that made their way 

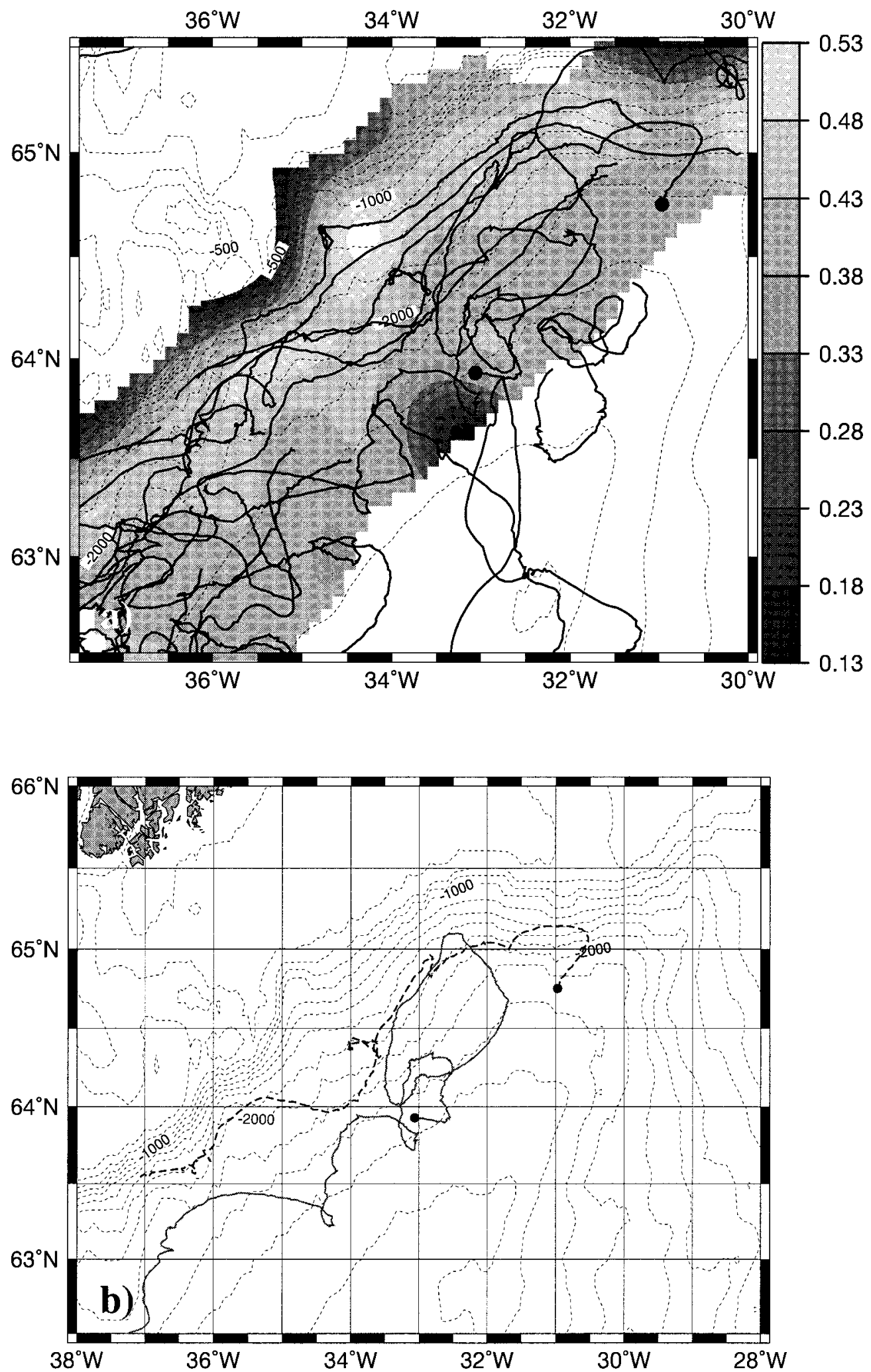

FIG. 1. Observations from the Irminger Basin. (a) Trajectories of satellite-tracked buoys at the East Greenland continental slope together with the dynamic topography 100/1000 dbar (redrawn from Krauss and Käse 1998). (b) Typical trajectory realizations for two drifters that moved on the upslope edge and on the downslope edge of the overflow plume, respectively. (c) Meridional density $\left(\lambda=34^{\circ} \mathrm{W}\right)$ section taken from an objectively analyzed dataset from the Poseidon 222 cruise. 


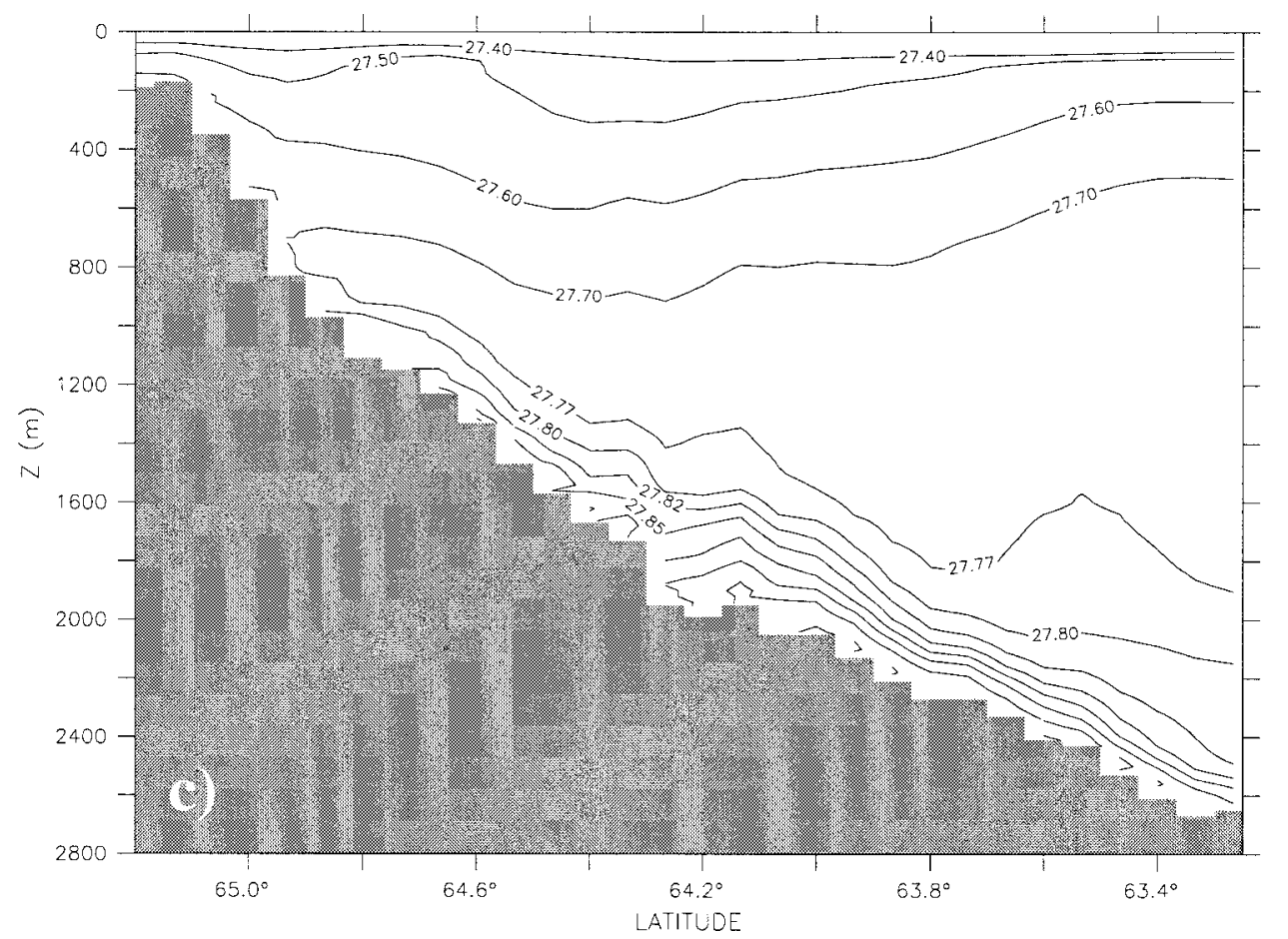

FIG. 1. (Continued)

to the south on the upslope and downslope side of the plume, respectively, are redrawn in Fig. 1b. Drifter 800, after it follows a huge recirculation loop in the beginning, was captured twice in an intensive cyclonic eddy. The eddy sizes, translation speeds and azimuthal speeds were comparable to those described by Krauss (1996). The upslope trajectory roughly followed the 1800-2000 $\mathrm{m}$ bottom contours. Near $64^{\circ} 20^{\prime} \mathrm{N}, 33^{\circ} 45^{\prime} \mathrm{W}$ it was pushed upslope and looped anticyclonically above the 1800-m contour line. Whereas the buoys are instantaneous realizations of the mesoscale variability, the dynamic topography gives a smoothed image, integrated over the time of the campaign. Nevertheless it shows chains of anticyclonic and cyclonic eddies along the overflow plume (Fig. 1a). The anticyclones (geopotential "highs") were generally located on the upslope side of the plume center and the cyclones (geopotential "lows") appeared on the downslope edge of the dense water vein. A meridional density section $\left(34^{\circ} \mathrm{W}\right)$ that cuts through the high at about $64.5^{\circ} \mathrm{N}$ and the low at $63^{\circ} \mathrm{N}$ shows the typical hydrographic structure of the western Irminger Basin where the overflow water hugs the continental slope (Fig. 1c). The overflow water $(\sigma$ $>27.8 \mathrm{~kg} \mathrm{~m}^{-3}$ ) extends from 900 to more than 2400 $\mathrm{m}$ and there is a pronounced core with densities $\sigma>$ $27.95 \mathrm{~kg} \mathrm{~m}^{-3}$ centered at 2200-m depth. Near the core the plume is asymmetric where the isopycnal shape is modified by downslope Ekman transport (Ezer and Weatherly 1990). The upslope isopycnals are relatively steep where they intersect the bottom, whereas the downslope edge is much smoother. The density structure of the overlying water masses reflect the geopotential height distribution. The high on the upslope side reflects the deepening of the deep isopycnals (e.g., $\sigma=27.7$ $\mathrm{kg} \mathrm{m}^{-3}$ and $\sigma=27.8 \mathrm{~kg} \mathrm{~m}^{-3}$ ). The anticyclone is thus located slightly upslope of the core, overlying a detached density maximum $\left(\sigma>27.87 \mathrm{~kg} \mathrm{~m}^{-3}\right)$. The isopycnals tend to follow the plume shape over the core but bend upward to form a huge dome above the downslope edge indicating cyclonic water movement at midlevels.

\section{The numerical model}

The Princeton Ocean Model (POM), a three-dimensional primitive equation model developed by Blumberg and Mellor (1987), is used for the experiments. The model utilizes the hydrostatic and Boussinesq approximation and has a free surface. It features a terrainfollowing vertical coordinate and an embedded turbulence submodel (Mellor and Yamada 1982). The model has been used for a wide range of oceanic applications from basin-scale experiments to small-scale process studies. Among the latter were a number of applications demonstrating the model's suitability for simulations of descending bottom flows (Jiang and Garwood 1996; Jungclaus 1999; Jungclaus and Mellor 2000). For more information on the model equations and numerical details the reader is referred to Blumberg and Mellor (1987).

In order to focus on the baroclinic instability of a dense bottom current we use a periodic channel with a 

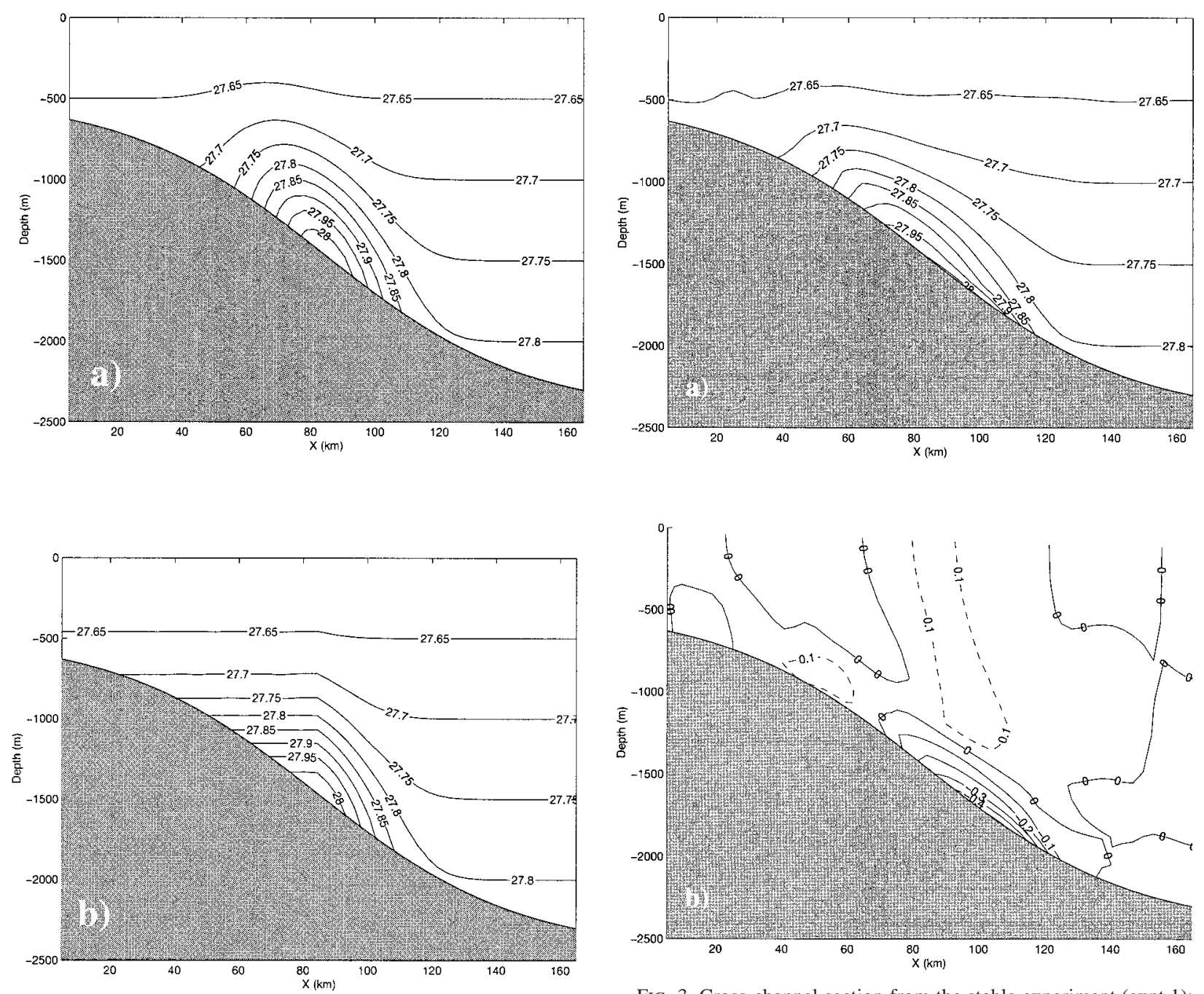

FIG. 3. Cross-channel section from the stable experiment (expt 1): (a) density (c.i. $=0.05 \mathrm{~kg} \mathrm{~m}^{-3}$ ) and (b) alongslope velocity [c.i. $=$ $0.05 \mathrm{~ms}^{-1}$; dashed lines indicate positive (northward) velocities].

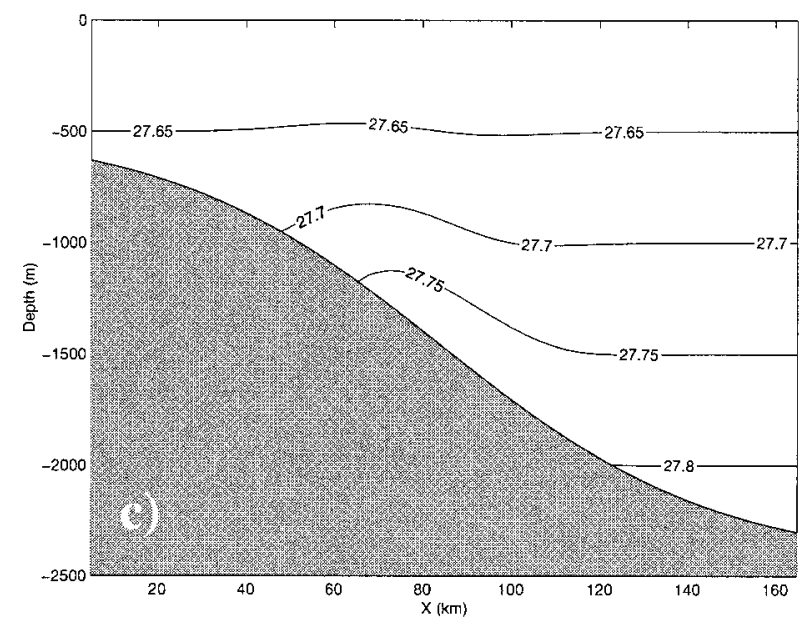

FIG. 2. Model topography and initial stratification: cross-channel section of density [contour interval $\left(c_{i}\right)=0.05 \mathrm{~kg} \mathrm{~m}^{-3}$ ] used for (a) expts 1, 2, and 5; (b) expt 3; and (c) expt 4. length of $300 \mathrm{~km}$ in the north-south direction and a width of $180 \mathrm{~km}$. The continental slope topography is given by

$$
H(x)=h_{1}-\frac{1}{2}\left(h_{1}-h_{2}\right)\left[1-\tanh \left(\frac{(90 \mathrm{~km}-x)}{62 \mathrm{~km}}\right)\right],
$$

where $h_{1}$ and $h_{2}$ are $2500 \mathrm{~m}$ and $500 \mathrm{~m}$, respectively. The maximum bottom slope $s^{*}$ is approximately $1.2 \times$ $10^{-2}$ in the standard configuration but is varied in the experiments of section 6 . The vertical sigma coordinate was originally represented by 24 levels but initial tests showed that a resolution of 12 levels gave virtually indistinguishable results and most experiments were therefore carried out with the low vertical resolution. The horizontal grid sizes $\Delta x$ and $\Delta y$ are $3 \mathrm{~km}$ and $3.125 \mathrm{~km}$, respectively. The western and eastern boundaries are closed. There is no surface forcing, and at the bottom we apply a quadratic frictional parameterization with a 
constant coefficient of $c_{d}=3 \times 10^{-4}$. This value is one order of magnitude smaller than the canonical value of $2.5 \times 10^{-3}$ often used in numerical models. Experiments with the original value gave qualitatively similar results, but downslope transport owing to Ekman veering was more pronounced and tended to blur some of the effects described below. A relatively low and spatially constant value for the horizontal (Laplacian) diffusion and viscosity $A_{H}=A_{M}=50 \mathrm{~m}^{2} \mathrm{~s}^{-1}$ was used, which acts along sigma coordinates. To minimize artificial cross-isopycnal diffusion mean $T(z)$ profiles are subtracted prior to the diffusion calculation (Mellor and Blumberg 1985). The density is assumed to depend solely on temperature, and a linear equation of state is used for our idealized experiments.

The temperature field consists of linearly stratified slope water lying above a denser layer of overflow water. The transition between the water masses is smooth and is expressed by Gaussian functions. At a sigma level $k$ ( $k=1, k_{b}$, where $k_{b}$ is the bottommost layer) the temperature distribution is given by

$$
\begin{aligned}
T(x, k)= & 6^{\circ}+\frac{z(k)}{2000 \mathrm{~m}} \\
& -3^{\circ} \exp \left[-\left(\frac{80 \mathrm{~km}-x}{50 \mathrm{~km}}\right)^{2}\right] \exp \left[-\left(\frac{k_{b}-k}{4}\right)^{2}\right] .
\end{aligned}
$$

The initial density field is shown in Fig. 2a. The core of the dense filament is situated in the middle of the slope where the topographic gradient is largest. The overflow water is more strongly stratified than the ambient water so that the overflow forms a high-potentialvorticity layer, a feature that is characteristic for the Denmark Strait overflow (Spall and Price 1998). If the filament were to be represented by a single layer as, for example, in the streamtube experiments of Price and Baringer (1994), our configuration would be comparable to their potential density contrast of $\Delta \rho \cong 0.2-0.25 \mathrm{~kg}$ $\mathrm{m}^{-3}$ after the entraining initial phase. The internal Rossby radius is roughly $10 \mathrm{~km}$. In all experiments the vorticity gradient induced by the sloping bottom is assumed to be more important than variations in the Coriolis parameter and therefore a constant Coriolis parameter $f=1.2 \times 10^{-4}$ is applied.

The model is started from a geostrophically balanced initial velocity field. The Gaussian-shaped filament of our standard configuration (Fig. 2a), chosen for comparison with earlier theoretical studies (Griffith et al. 1982; Swaters 1991), results in a northward return flow on the upslope side of the plume. To show that our results hold also for a more unidirectional flow like the Denmark Strait overflow plume, we carried out an additional experiment using the configuration shown in Fig. 2b. We discuss also the results of a case with considerably smaller initial density contrast (Fig. 2c). The experiments we used to study the destabilization and the nonlinear eddy evolution are summarized in Table
TABLE 1. List of the basic destabilization experiments.

\begin{tabular}{cc}
\hline \hline Expt & Remarks \\
\hline 1 & Gaussian-shaped filament (Fig. 2a), no perturbation \\
2 & as in expt 1 but sinusoidal perturbation: the "standard ex- \\
periment" \\
3 as in expt 2 but half Gaussian-shaped filament (Fig. 2b), no \\
return flow at the upslope edge \\
4 as in expt 2 but small initial density contrast (Fig. 2c) \\
5 as in expt 2 but no advection of momentum
\end{tabular}

1. An additional series of experiments (Table 2) is discussed in section 6 where we concentrate on the parameter dependence of the growth rate.

\section{A stable filament}

We start with a reference experiment. If we do not perturb the filament by either random or sinusoidal initial deviations from the alongslope mean, we create a stable density-driven flow. After the initial adjustment that is associated with a decrease in total height and a downslope slumping of the dense core, the density field remains almost constant (save for some inertial oscillations) over the duration of the experiment (20 days). Figure 3a shows a density section after 9 days of simulation. The downslope excursion of the heavy plume water and the partial collapse of the filament has not introduced vortical motion. The alongslope velocity section shows an unperturbed baroclinic flow field. The pressure gradients owing to the sloping isopycnals induce northward velocities on the upslope side and southward velocities on the downslope side of the filament (Fig. 3b). Near the bottom the topographic slope enhances the flow on the downslope side whereas it reduces the effective pressure gradient on the upslope side. Maximum southward velocities occur near the bottom of the downslope front and exceed $0.4 \mathrm{~m} \mathrm{~s}^{-1}$. The southward-flowing layer has a thickness of about $300 \mathrm{~m}$ and a density $\sigma>27.8 \mathrm{~kg} \mathrm{~m}^{-3}$. The flow structure is baroclinic with maximum northward velocity situated directly above the fast-flowing southward core. A similar baroclinic structure can be seen in the oppositely directed flows on the upslope edge of the filament.

\section{The unstable overflow filament}

\section{a. Temporal evolution of the instability}

The initial temperature distribution is now modified by superimposing a sinusoidal perturbation to the temperature anomaly, so that (2) becomes

$$
\begin{aligned}
T(x, y, k)= & 6^{\circ}+\frac{z(k)}{2000 \mathrm{~m}} \\
& -3^{\circ} \exp \left[-\left(\frac{80 \mathrm{~km}-d \sin (2 \pi y / \lambda)-x}{50 \mathrm{~km}}\right)^{2}\right] \\
& \times \exp \left[-\left(\frac{k_{b}-k}{4}\right)^{2}\right]
\end{aligned}
$$



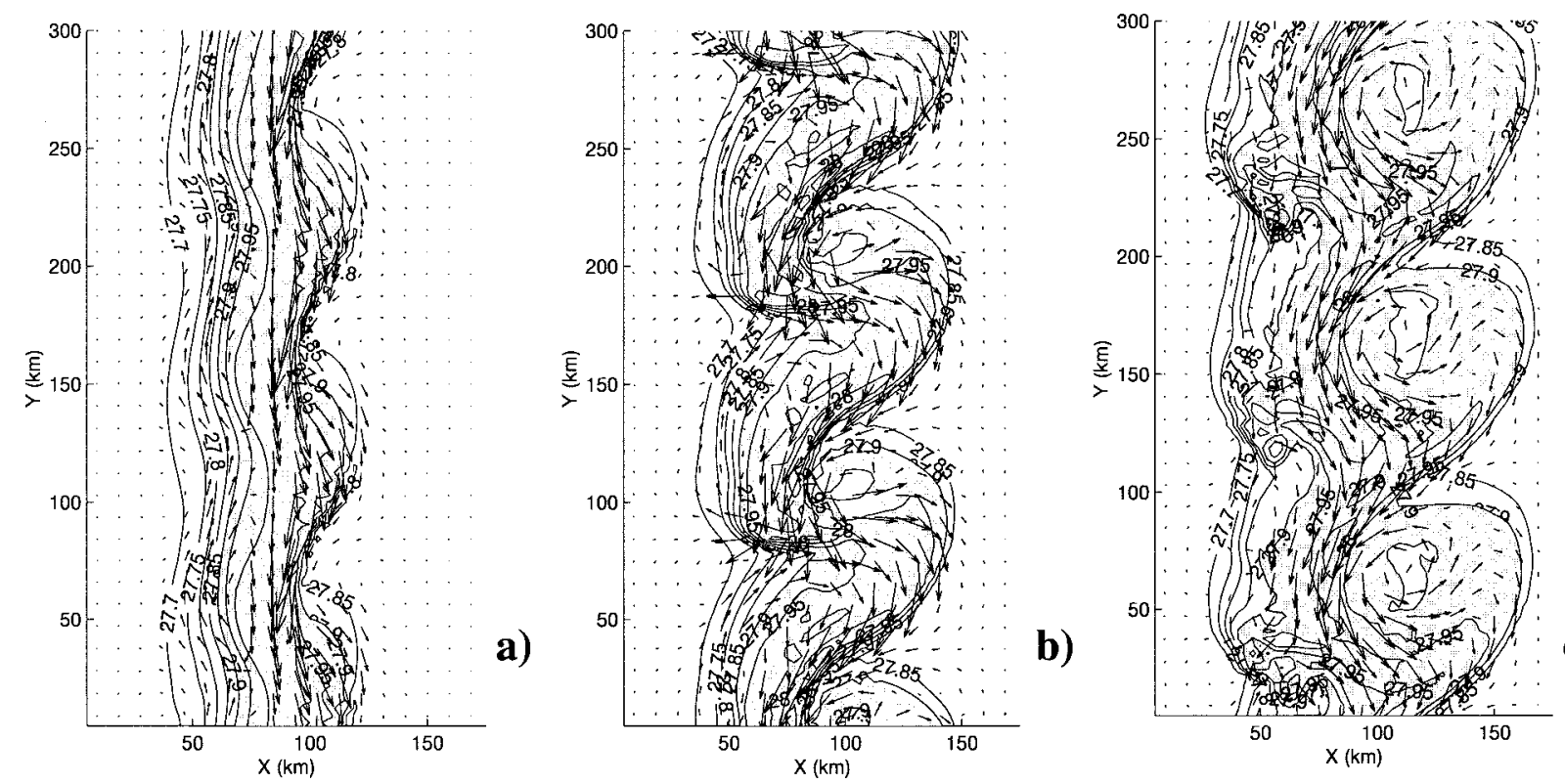

FIG. 4. Evolution of the bottom density field (c.i. $=0.05 \mathrm{~kg} \mathrm{~m}^{-3}$, values $>27.9 \mathrm{~kg} \mathrm{~m}^{-3}$ shaded) together with current vectors (max vector $=0.5 \mathrm{~m} \mathrm{~s}^{-1}$ ) after (a) 2 days, (b) 5 days, and (c) 8 days of simulation from the unstable experiment (expt 2).

where $\lambda$ is a prescribed wavelength (in $\mathrm{km}$ ) and $d$ is the amplitude of the perturbation. The theoretical study and the laboratory experiments of Griffiths et al. (1982) suggest that the most unstable wavelength is expected to be about seven to eight times the baroclinic Rossby radius. Here we choose $\lambda=100 \mathrm{~km}$ as an initial guess. The dependence of the maximum growth rate on the perturbation wavelength shall be discussed in more detail in section 6. The amplitude was chosen to be one horizontal grid distance $(3 \mathrm{~km})$.

The temporal evolution of the near-bottom (layer 11) density is given in Fig. 4 together with the current vectors of the bottom flow. In Fig. 5 we show the corresponding development of the upper layer by showing the surface elevation and the near-surface currents. During the first two days (Fig. 4a) the horizontal phase difference between the upslope and downslope edge results in a subsequent thinning and thickening of the filament. Inside the overflow layer the thermal wind balance requires that anticyclonic flow evolves around accumulations of dense water (at $y=50 \mathrm{~km}, 150 \mathrm{~km}$, and $250 \mathrm{~km}$ ). At this stage the flow resembles the "varicose" mode of Griffiths et al., and one could speculate that the filament could break up into a number of anticylones as in the case of the relatively narrow coupled front described by Griffiths et al. However, the further development ( $t=5$ days, Fig. 4c) shows that eddies of both sign form and that the mature state $(t=8$ days, Fig. 4c) is characterized by strong cyclones on the downslope side and somewhat weaker anticyclones on the upslope side of the density current. Although the horizontal phase difference of the lateral fronts appears to be primarily responsible for the initial growth of the deformation, the dislocation of the dense bottom layer has started immediately to act on the upper layer by the mechanism of vortex stretching and compression. Figure 5a ( $t=2$ days) shows clearly that at those locations where the relatively dense and highly stratified bottom water slumps down (Fig. 4a; $x=110 \mathrm{~km} ; y=20 \mathrm{~km}$, $120 \mathrm{~km}$, and $220 \mathrm{~km}$ ) the upper layer is compressed and anticyclonic vorticity is induced. Figures $4 \mathrm{a}$ and $5 \mathrm{a}$ resemble qualitatively Karsten et al.'s (1995) picture of the spatial structure of the unstable modes. In their Fig. 7 the local extrema in the upper-layer pressure field take the form of alternating cyclones and anticyclones. Deformations in the lower-layer thickness contours are most pronounced on the downslope side of the density current and the upper layer extrema are displaced in the downstream direction of the bottom flow.

During the nonlinear eddy growth the upper and lower layer extrema become more and more vertically aligned. After 5 days this can be seen in the horizontal fields, comparing Figs. $4 \mathrm{~b}$ and $5 \mathrm{~b}$. At this time intense dipolar structures have evolved in the bottom flow with centers of cyclonic vorticity at $x=110 \mathrm{~km} ; y=110 \mathrm{~km}, 210$ $\mathrm{km}$, and anticyclonic motion at $x=75 \mathrm{~km}, y=60 \mathrm{~km}$, $170 \mathrm{~km}$, and $270 \mathrm{~km}$. Comparing Figs. 4a and 4b we see that the centers of the cyclonic vortices were initially located outside the dense filament. Overflow water is then wrapped around the cyclone, and we find a pool of ambient water $\left(\sigma<27.9 \mathrm{~kg} \mathrm{~m}^{-3}\right)$ in the center. The evolution of the cyclonic eddy has lead to a considerable downslope spreading of the overflow water. The most vigorous southward flow is found in the highly confluent regions upstream of the cyclones. In contrast, the upslope density front is no longer a center of organized northward flow. Anticyclonic motion is concentrated around the high-density boluses. They are now found 

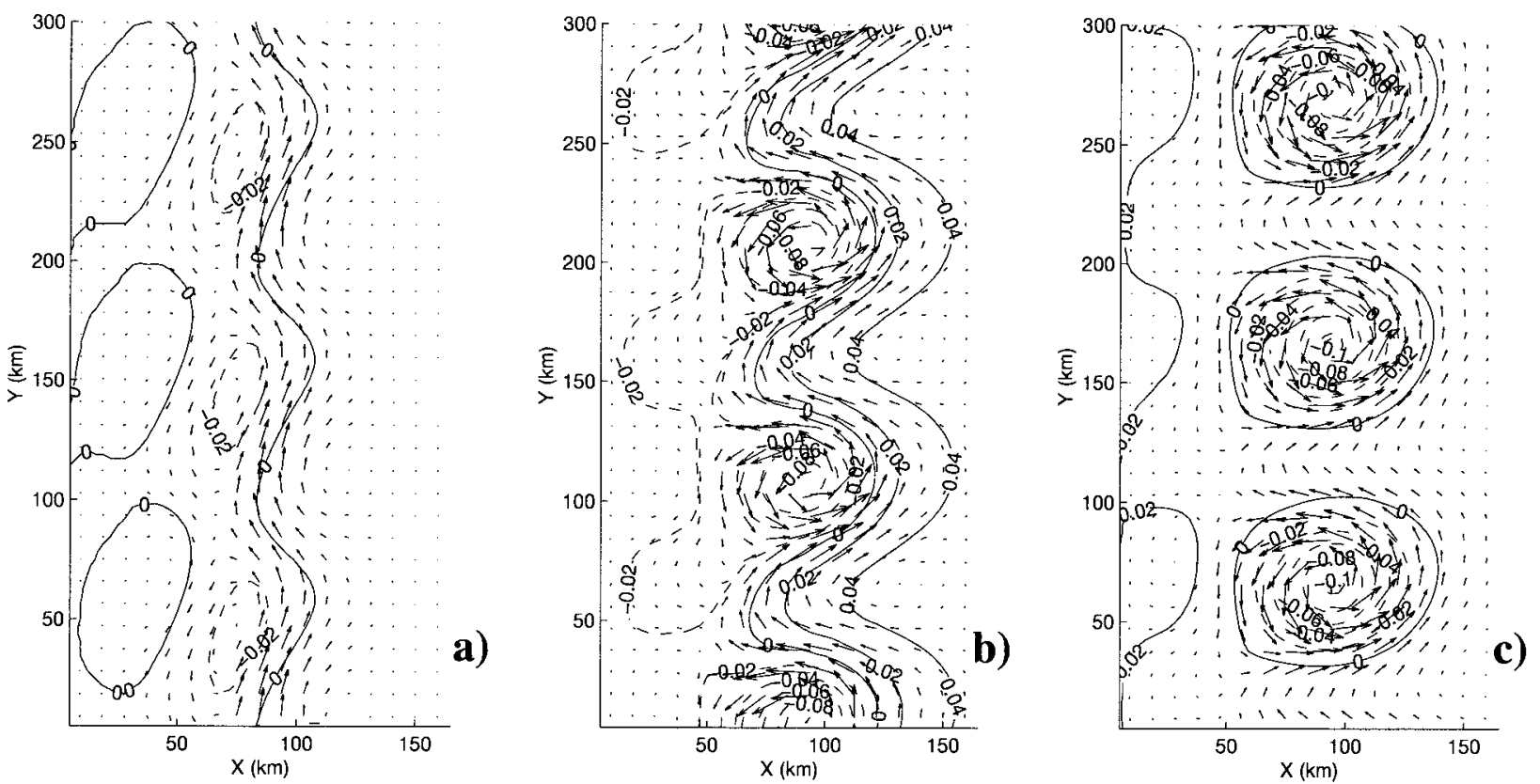

FIG. 5. Evolution of the surface elevation $($ c.i. $=0.02 \mathrm{~m})$ together with current vectors $\left(\max\right.$ vector $\left.=0.15 \mathrm{~m} \mathrm{~s}^{-1}\right)$ after $(\mathrm{a}) 2$ days, $(\mathrm{b}) 5$ days, and (c) 8 days of simulation from the unstable experiment (expt 2).

slightly upslope of the original center of the filament. This upslope-moving tendency continues and Fig. 4c shows the situation after 8 days of simulation. Now the densest water is found in relatively small blobs at $x=$ $60 \mathrm{~km} ; y=35 \mathrm{~km}, 120 \mathrm{~km}$, and $220 \mathrm{~km}$. The cyclones have not moved considerably farther downslope and their axis lies at $x=110 \mathrm{~km}$. It is interesting that the mean bottom flow did not break off into a chain of eddies. Rather, the southward bottom flow becomes realigned between eddies of different sign approximately at the location of the original filament. Note, however, that the dense bottom water flow here is entirely southward in contrast to the stable filament. The further evolution of the surface elevations (Figs. $5 b$ and $5 c$ ) parallels the vortex formation in the lower layer. Depressions indicate cyclonic eddies. At day 8 the maximum surface depressions related to the cyclones are about 10 $\mathrm{cm}$ whereas the highest positive anomalies are less than $2 \mathrm{~cm}$. During their nonlinear development the eddies become more and more vertically aligned. The considerable phase difference between the upper layer and the perturbations in the density current in the beginning of the destabilization is a typical feature of a baroclinically unstable two layer system and a necessary condition for the release of potential energy from the mean flow into the growing waves (e.g., Gill 1982). Since the topographic slope provides the background vorticity gradient, we see here an analogy to the westward shift with height associated with unstable baroclinic waves in the atmosphere (Bush et al. 1995). The vertical phase shift is quickly eroded and after 5 days (Figs. $4 \mathrm{~b}$ and $5 \mathrm{~b}$ ) the flow structure is nearly barotropic.

The bottom flow at the later stage of development is characterized by chains of eddies of opposite signs on the downslope and upslope side of the filament. The bottom flow between the eddy streets is entirely southward and the eddies become more and more barotropic during their development. Therefore the eddies are not simply superimposed on the initial mean flow but substantially alter the entire flow field. This becomes evident in comparing a cross-channel section (Fig. 6) to the respective one for the undisturbed flow (Fig. 3). Figure 6 shows a snapshot of density (Fig. 6a) and alongslope velocity (Fig. 6b) taken at $t=9$ days and $y=120 \mathrm{~km}$. Water with a density $\sigma>27.9 \mathrm{~kg} \mathrm{~m}^{-3}$ is found in the center and in a detached maximum at the downslope edge where the cyclone has advected overflow water downslope. The original density field of Fig. 2a has been torn apart by the cyclonic eddy. Thus, the eddies form an effective means of downslope transport that is apparently more effective than bottom friction. The velocity field (Fig. 6b) shows even stronger distortion from the undisturbed field in Fig. 3b. The most dominant features are the cyclonic eddy centered around $x=110 \mathrm{~km}$ and the fast flowing core in the center of the slope. The anticyclonic motion near the bottom is centered around $x=40 \mathrm{~km}$. The eddy travels with the mean flow so that the upslope side of the eddy manifests itself in the minimum of along-slope velocity at $x=40$ $\mathrm{km}$. The density structure reflects the mesoscale motion, and we find a doming of isopycnals associated with the cyclone and a dip-down of the $\sigma=27.7 \mathrm{~kg} \mathrm{~m}^{-3}$ isopycnal directly above the dense blob at $900 \mathrm{~m}$ (at $x=$ $40 \mathrm{~km}$ ). Although our model setup is highly idealized, the simulated density field shows a remarkable resemblance to the observed section of Fig. 1c. 

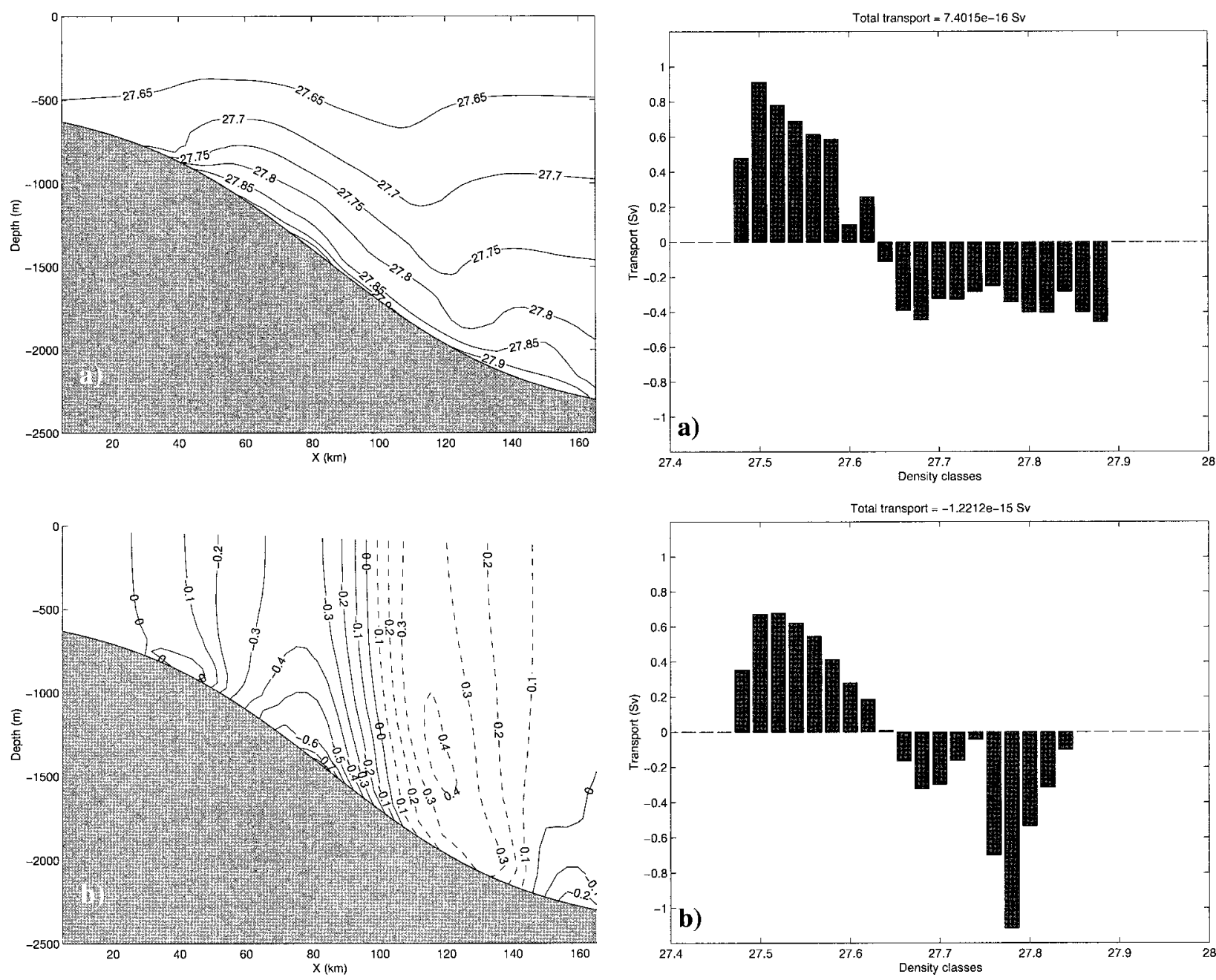

FIG. 6. Cross-channel section ( $y=160 \mathrm{~km}, T=9$ days) from the unstable experiment (expt 2): (a) density (c.i. $=0.05 \mathrm{~kg} \mathrm{~m}^{-3}$ ) and (b) alongslope velocity [c.i. $=0.05 \mathrm{~m} \mathrm{~s}^{-1}$; dashed lines indicate positive (northward) velocities].

The alongslope velocity field possesses a pronounced core of southward flow at $x=75 \mathrm{~km}$. Here the maximum velocity exceeds $70 \mathrm{~cm} \mathrm{~s}^{-1}$, more than $30 \%$ higher than the respective velocity in the stable filament of Fig. $3 \mathrm{~b}$. This intensification, also seen in Fig. 4c, reflects an energy transfer from the eddies to the mean flow. The wave growth converts mean potential energy into eddy kinetic energy. As the wave grows to the finite amplitude stage, an energy transfer from the eddy field to the mean field accelerates the density current. This sequence of transfers has been described for a buoyant coastal current by Qui et al. (1988).

The translation speed of the eddies was deduced from a space-time diagram (not shown). In the periodic model domain, regular reoccurring structures evolve and the translation speed is nearly constant and is roughly 0.2 $\mathrm{m} \mathrm{s}^{-1}$. This can be compared with the Nof speed $c_{\text {Nof }}$ $=g^{\prime} s^{*} / f$ (Nof 1983). Using the initial density contrast

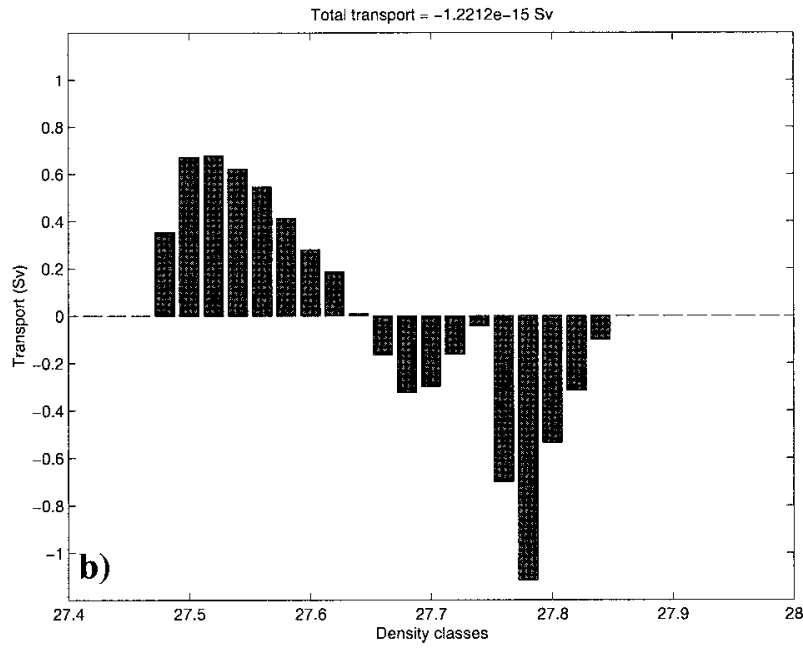

FIG. 7. Distribution of mass transports (in Sv) binned in density classes. Time-mean (day 10-day 16) of northward and southward transport for (a) the stable experiment and (b) the unstable experiment.

of about $0.25 \mathrm{~kg} \mathrm{~m}^{-3}$ and the other parameters as given in section 3 we obtain $c_{\mathrm{Nof}}=0.25 \mathrm{~m} \mathrm{~s}^{-1}$. Of course, the two-layer vertical structure does not hold after eddy formation and mixing and, therefore, the model's lower value is reasonable.

\section{$b$. The effect of the eddies on water mass modification}

So far, we have pointed out that the eddies modify the density and velocity field considerably. One effect is the cross-slope spreading of overflow waters by the cyclonic vortices that was seen during the early stage of the destabilization (Figs. 4a,b). After the eddies have formed, the self-propelling mechanism described by Nof (1983) leads to eddy propagation basically along the lines of constant depth. Now the eddies transport the water mass properties that they capture during the initial 

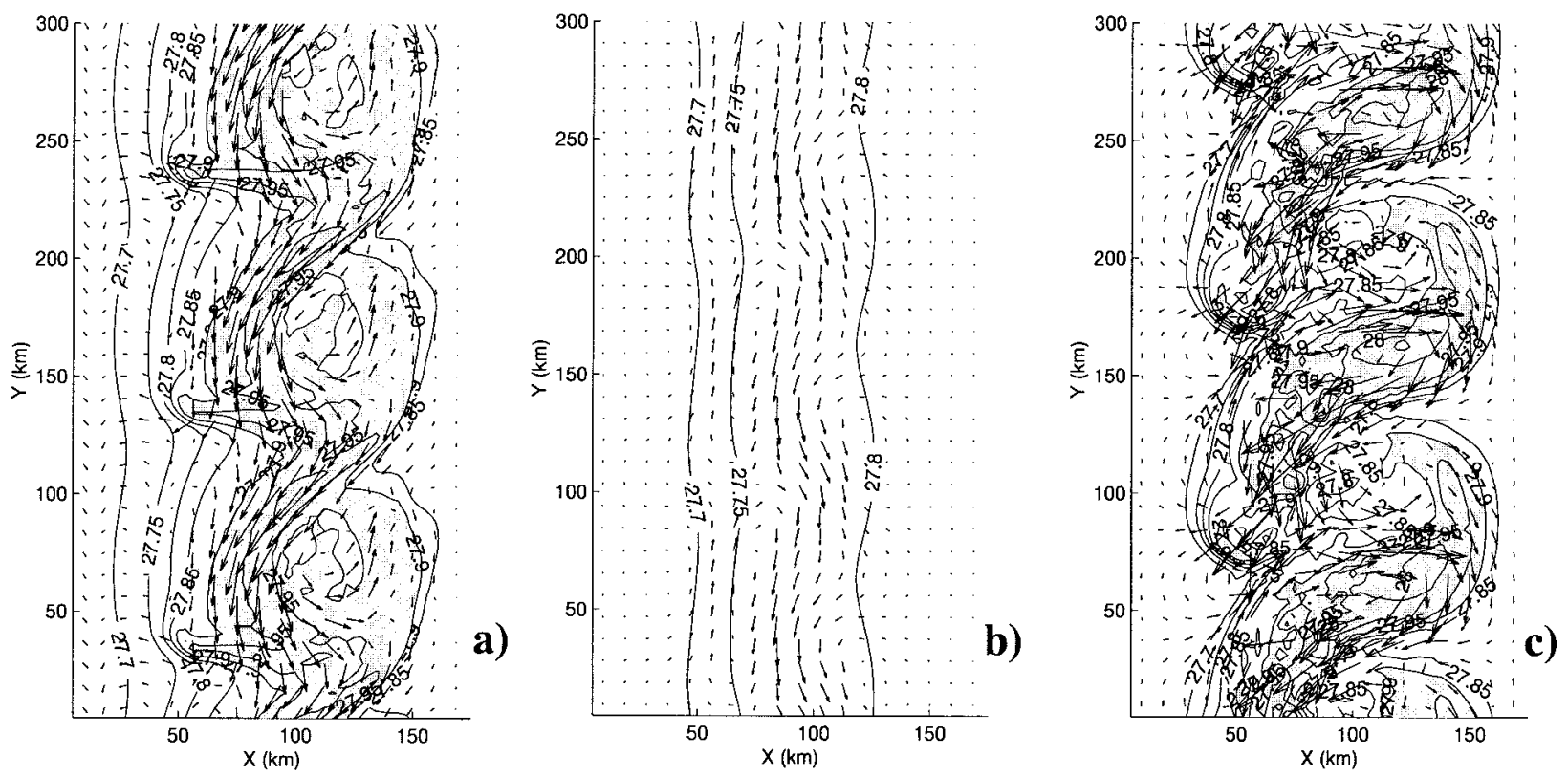

FIG. 8. Bottom density field (c.i. $=0.05 \mathrm{~kg} \mathrm{~m}^{-3}$; values $>27.9 \mathrm{~kg} \mathrm{~m}^{-3}$ shaded) together with current vectors after 8 days of simulation for (a) expt 3, (b) expt 4, and (c) expt 5. In (a) and (c) $\max$ vector $=0.5 \mathrm{~m} \mathrm{~s}^{-1}$; in (b) $\max$ vector $=0.15 \mathrm{~m} \mathrm{~s}^{-1}$.

development (Fig. 4c). The anticyclones upslope of the flow center are rich in overflow water and may be related to the boluses of dense water often observed in the overflow. They resemble the centers of cold bottom temperature from the Poseidon data. Like the anticyclonic Mediterranean outflow eddies (meddies) they may transport dense water over a large horizontal distance (Armi and Zenk 1984). On the other hand, the cyclones were shown to be a mixture of overflow and ambient slope water. They are an effective means of mixing. To see the impact of the eddies on the overflow transport the southward transports were binned in density classes and averaged over the time $\operatorname{span} t=10$ to 16 days. Figure 7 a shows the result for the experiment where no eddies were formed and Fig. $7 \mathrm{~b}$ to our standard experiment. The eddy case differs in two important aspects: 1) The highest density classes are eroded by additional mixing and 2) there are two peaks of southward flow in the overflow water. The most pronounced occurs near $\sigma=$ $27.9 \mathrm{~kg} \mathrm{~m}^{-3}$ and can be attributed to the southward flow focused over the original center of the filament (see Fig. $6 \mathrm{~b}$ ). The somewhat less dense maximum reflects the waters captured in the cyclonic eddies.

\section{c. The dominance of cyclonic eddies}

A number of experiments was carried out to make sure that the findings reported in the previous section were not just a result of the specific model settings and to understand the cyclogenetic mechanism. Here we describe three experiments in detail (cf. Table 1). In experiment 3 we used the initial configuration (Fig. 2b) that does not require a northward return flow on the upslope side of the filament. In experiment 4 the density contrast between the plume and the ambient water was drastically reduced (Fig. 2c) by decreasing the amplitude of the temperature anomaly [Eq. (3)] from $3^{\circ}$ to $0.5^{\circ}$. For experiment 5 the original configuration was used but the advection of momentum was switched off in the model. The results of these runs are displayed in Figs. 8 (the near-bottom flows and density fields after 8 days of simulation) and 9 (the respective surface elevations).

Although the initial condition in experiment 3 differs considerably in terms of the horizontal velocity shear in the plume layer, the overall result (Figs. 8a and 9a) is similar to the standard experiment (Fig. 4c). In particular, the cyclonic eddies are stronger and most pronounced in terms of surface elevation (Fig. 9a). The nonlinear eddy formation process therefore is not an artifact of the relatively strong horizontal velocity shear of our standard configuration; rather, the evolution becomes quickly independent of the initial condition during the growth phase.

This is not the case, however, for the "linear" experiments 4 and 5. Also in the small perturbation experiment (expt 4) persistent cyclones and anticyclones develop but they are of similar strength (Fig. 9b). Here the alternating cyclones and anticyclones both show surface elevations of about $4 \mathrm{~mm}$. The small perturbations obviously favor a more linear response, and we find again a similarity to the linear solution depicted in Karsten et al. (1995). Another case study is performed in experiment 5 . Although we cannot entirely linearize the model (because there is advection of density) neglecting the momentum advection reduces the nonlinear advec- 

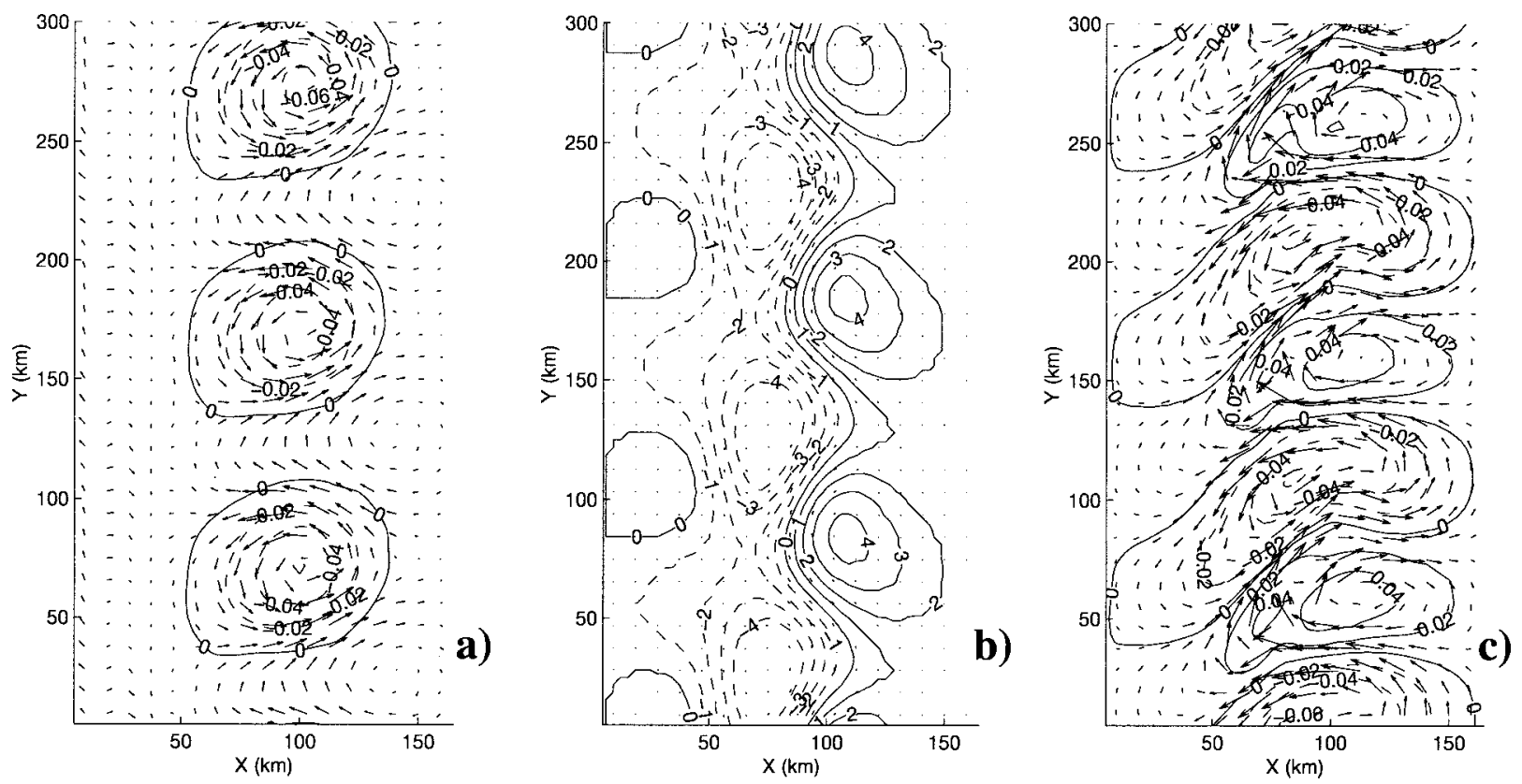

FIG. 9. Surface elevation (c.i. $=0.02 \mathrm{~m}$ ) together with current vectors after 8 days of simulation for (a) expt 3 , (b) expt 4, and (c) expt 5. In (a) and (c) c.i. $=0.02 \mathrm{~m}$; in (b) c.i. $=1 \mathrm{~mm}$.

tion of relative vorticity. The bottom flow in Fig. 8c shows a similar, if not larger, downslope slumping during the eddy growth compared with the standard experiment (Fig. 4c). However, anticyclones and cyclones are equally strong (Fig. 9c) with depressions and elevations of up to $5 \mathrm{~cm}$. Therefore the intensification of the cyclones is primarily an effect of the nonlinear eddy formation.

To inspect the cyclogenetic process the evolution of relative vorticity (normalized by $f$ ) is shown in a moving frame during the formation of a cyclone in the standard experiment (Figs. 10a-c). At $t=2$ days (Fig. 10a) we see a developing anticyclone within the filament and a developing cyclone outside the filament (cf. Figs. 4a and $4 \mathrm{~b}$ ). The downslope motion seen around $y=160$ $\mathrm{km}$ is clearly associated with cyclonic vorticity and reflects the vortex stretching of the lower layer as it slumps down. However, the highest values of positive vorticity are found farther to the north in the upstream front. The downslope edge even of the undisturbed filament is a maximum of cyclonic vorticity owing to the shear in the horizontal velocity (Fig. 4a). The confluence of anticyclonic flow inside the filament and cyclonic flow outside the filament sharpens the front locally. One day later (Fig. 10b) the positive frontal vorticity is incorporated into the cyclone that continues to intensify (Fig. 11c). At $t=5$ days Fig. 10b clearly shows that these frontal waters, carrying high positive relative vorticity, are incorporated into the eddy by cyclonic wrapping.

In a study comparing semigeostrophic- and primitiveequation-simulated wave growths, Snyder et al. (1991) found that the semigeostrophic model was unable to reproduce the cyclonic wrapping and the vertical align- ment of cyclones that is characteristic for frontal cyclogenesis in the atmosphere. Snyder et al. concluded that nonlinear evolution during cyclogenesis relies on the advection of ageostrophic vorticity into the cyclone, a dynamical factor absent in the more simplified model. When the authors applied the full primitive-equation model, the cyclones were more intense than the anticyclones and the bottom and top disturbances appeared vertically aligned, very similar to our case of a bottom jet in the ocean.

To explain the dominance of cyclones Krauss and Käse (1998) gave a simple potential vorticity (PV) conservation argument: The small downslope movements of the eddies are associated with an increase of the water column height $H$. For an anticyclone, PV conservation $\left(f-\left|\zeta_{a}\right|\right) / H=$ const implies that $\left|\zeta_{a}\right|$ must decrease, whereas for a cyclone $\left(f+\left|\zeta_{c}\right|\right) / H=$ const requires increasing $\left|\zeta_{c}\right|$. In the appendix, we elucidate the role of PV conservation further and relate this argument to our finding of the prominent role of the nonlinear eddy formation process.

\section{Growth rate and parameter dependence of the most unstable mode}

Swaters (1991) developed a theoretical two-layer model and presented a linear stability analysis for a dense bottom vein on a sloping continental shelf. For a parabolic coupled density front, the linear equations could be solved exactly and the spatial and temporal characteristics of the unstable modes described. Karsten et al. (1995) applied the Swaters model to the dense bottom current in the Strait of Georgia and calculated 

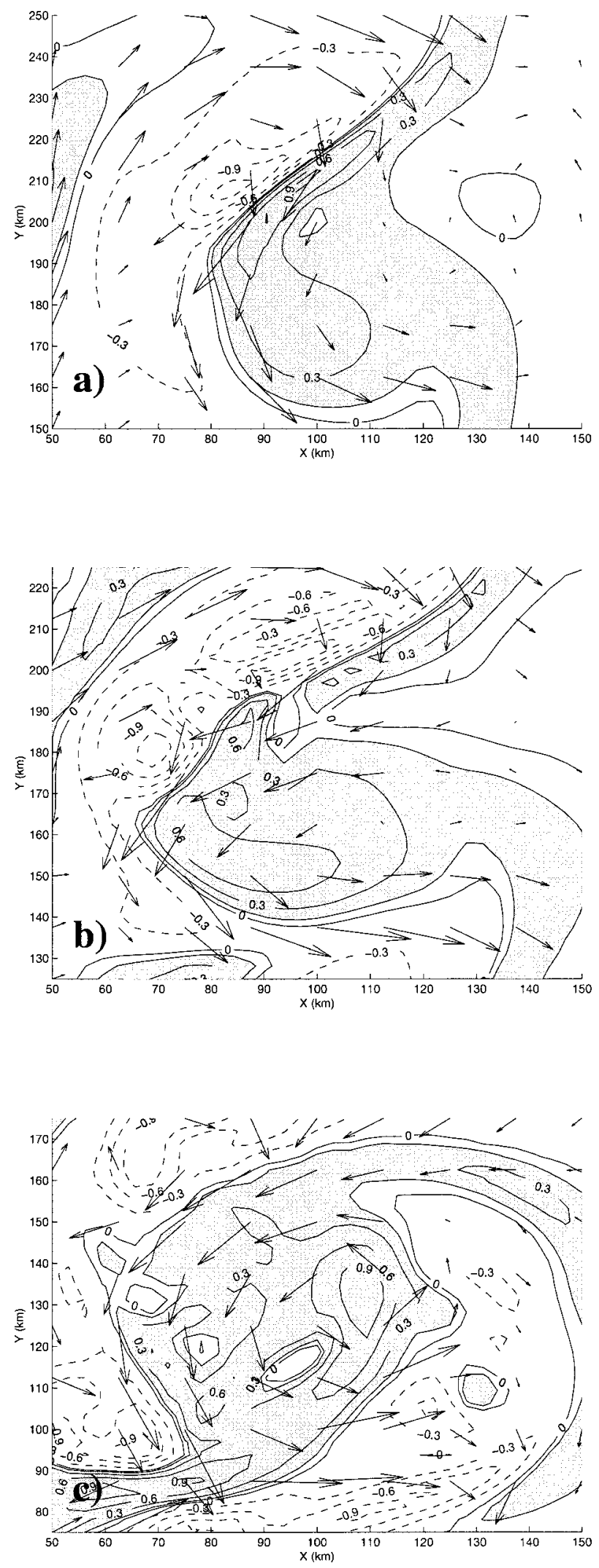

FIG. 10. Relative vorticity (normalized by $f$ ) during the evolution of one cyclonic eddy after (a) 2 days, (b) 3 days, and (c) 5 days.
TABLE 2. List of the growth-rate experiments: Parameter dependence on the intial density contrast $\Delta \rho$, the topographic slope $s^{*}$, and the interaction parameter $\mu$. Results are the cutoff wavelength $\lambda_{\min }$ [from Eq. (8)], the maximum growth rate, and the wavenumber and wavelength at the maximum growth rate (from the model).

\begin{tabular}{lccccc}
\hline \hline & \multicolumn{5}{c}{ Expt } \\
\cline { 2 - 6 } & 2 & 6 & 7 & 8 & 9 \\
\hline$\Delta \rho\left(\mathrm{kg} \mathrm{m}^{-3}\right)$ & 0.25 & 0.25 & 0.25 & 0.5 & 0.125 \\
$s_{\max }^{*}\left(\times 10^{-2}\right)$ & 1.2 & 0.6 & 1.8 & 1.2 & 1.2 \\
$\mu$ & 1.25 & 1.8 & 1.04 & 0.96 & 1.8 \\
$\lambda_{\min }(\mathrm{km})$ & 20 & 37 & 34.5 & 92 & 25 \\
$\sigma_{\max }\left(\mathrm{day}^{-1}\right)$ & 1.38 & 1.04 & 1.43 & 1.2 & 1.05 \\
$k\left(\sigma_{\max }\right)$ & 1.26 & 2.3 & 0.7 & 1.02 & 1.6 \\
$\lambda\left(\sigma_{\max }\right)(\mathrm{km})$ & 100 & 82 & 155 & 158 & 45 \\
\hline
\end{tabular}

characteristic wavenumbers and the spatial structure of the unstable modes. Since the focus of this paper is the nonlinear evolution of eddies in the Denmark Strait overflow, we recall here only Swaters' high-wavenumber cutoff and the bounds for growth rates and compare qualitatively the scales of our experiments with the parameter range described in Swaters (1991) and Karsten et al. (1995).

The dimensional parameters in the Swaters model are the bottom slope $s^{*}$, the height of the parabolic density current $h^{*}$, the total water depth $H^{*}$, the density contrast between the dense filament and the surrounding slope water $\Delta \rho^{*}$, and the width of the gravity current $l^{*}$. For our experiment we use $s^{*} \approx 1.2 \times 10^{-2}, h^{*} \approx 300 \mathrm{~m}$, $H^{*} \approx 2500 \mathrm{~m}, \Delta \rho^{*} \approx 0.25 \mathrm{kgm}^{-3}$, and $l^{*} \approx 40 \mathrm{~km}$. The velocity scale is given by the Nof speed $c_{\text {Nof }}=$ $g^{\prime} s^{*} / f \approx 0.22 \mathrm{~m} \mathrm{~s}^{-1}$ and the horizontal length scale by $L^{*}=\left[H^{*} U^{*} /\left(f s^{*}\right)\right]^{1 / 2}$ (Karsten et al. 1995). With these values we calculate Swaters' (1991) baroclinic interaction parameter $\mu=h^{*} /\left(s^{*} L^{*}\right) \approx 1.25$. The dimensionless width $l=l^{*} / L^{*}$ is used to calculate the high wavenumber cutoff

$$
k \leq k_{\max }=\frac{2 \mu^{1 / 2}+(l+4 \mu)^{1 / 2}}{l^{1 / 2}},
$$

following Karsten et al. (1995). According to these authors and Swaters the value of $k_{\max }$ is an overestimate of the actual wavenumber cutoff. Using the dimensional values given above we find $k_{\max } \approx 6.4$, a dimensionless wavelength $\lambda \approx 1$, and therefore a dimensional wavelength of $20 \mathrm{~km}$. Thus all perturbations with a wavelength shorter than $20 \mathrm{~km}$ are supposed to be stable in the Swaters model.

A series of experiments has been conducted varying the bottom slope and the density contrast. Each experiment consisted of numerous short runs during which a wavelength range from 20 to $360 \mathrm{~km}$ was covered. Additional refinements were applied near the peak values. The growth rate of the perturbations is calculated from the temporal evolution of the eddy kinetic energy $E^{\prime}=$ $E-E_{\text {mean }}$, where $E_{\text {mean }}$ is the alongslope average of the kinetic energy using 


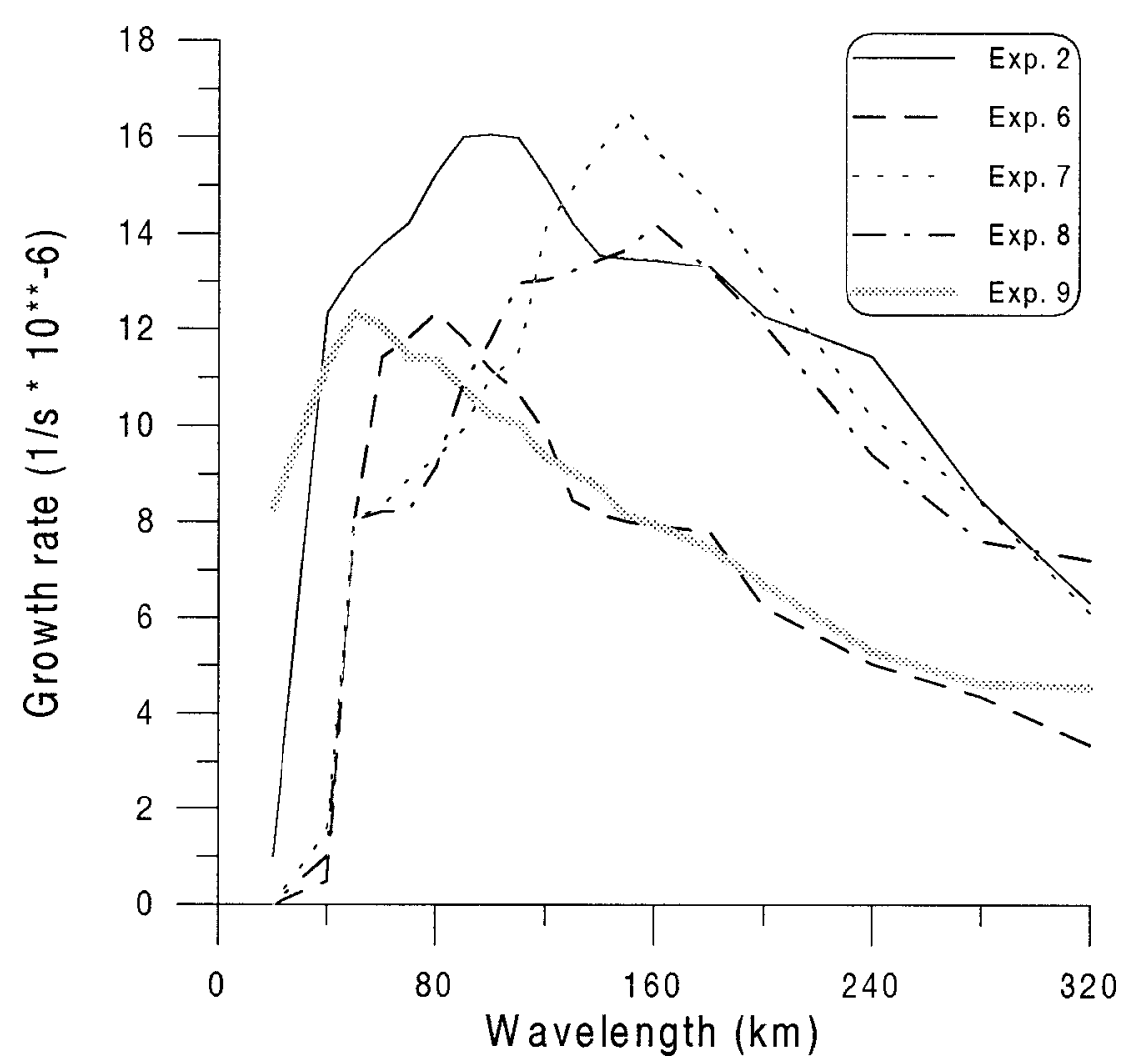

FIG. 11. Growth rate during the linear wave growth for the experiment series indicated in Table 2.

$$
\sigma=\frac{\partial \ln E^{\prime}}{2 \partial t} .
$$

In the model the kinetic energy was stored every hour and the growth rate was calculated during the time when the growth was exponential (usually between day 1 and 2 ). The growth rate curves are given in Fig. 11 and the respective experimental parameters are given in Table 2. The curves resemble qualitatively those of Swaters (1991) and Karsten et al. (1995). There is a pronounced maximum growth rate at a certain wavelength. Therefore the process of eddy formation is space selective. In the standard experiment the growth rate of the most unstable wave is $1.4 \mathrm{day}^{-1}$, that is, an $e$-folding time of about $17 \mathrm{~h}$. The corresponding dimensionless wavenumber is 1.26 and the dimensional wavelength is 100 $\mathrm{km}$.

Figure 11 demonstrates a pronounced sensitivity to the bottom slope and the density difference between the gravity current and the surrounding slope water. Increasing the bottom slope corresponds to decreasing the interaction parameter $\mu$ and, according to the Swaters theory, to smaller values of the most unstable wavenumber $k_{\max }$. Similarly, a change in the density contrast affects the Nof speed and the dimensional length scale $L^{*}$ with stronger density contrast resulting in longer length scales. Therefore an increase in $\Delta \rho$ corresponds to a decrease in $\mu$ and again to smaller maximum wavenumbers (or longer wavelengths of the most unstable mode). Whereas the simulated wavelength shows a similar sensitivity to changes in the interaction parameter, this is not the case for the growth rates. In the Swaters linear model the growth rate was roughly proportional to the interaction parameter $\mu$. Here we find the highest growth rates in the experiment with the steepest bottom slope (expt 7). In this case the horizontal velocities (and shears) are highest, the nonlinearities are more pronounced (higher Rossby number), and the wave evolves more rapidly. The accelerating effect of the steeper slope is obviously more pronounced than the stabilizing effect of an increased background vorticity gradient (here the topographic beta effect).

The parameter range used here suggests that in the Denmark Strait overflow finite amplitude vortices with a diameter between 25 and $200 \mathrm{~km}$ could be generated by baroclinic instability of the type described here. This length scale range and the propagation velocity of the eddies fit well in the observation from satellites (Bruce 1995) and near-surface drifters.

\section{Conclusions}

The nonlinear evolution of perturbations in the overflow plume and the subsequent eddy formation result 
in a flow structure that agrees with the observed mesoscale circulation above the Denmark Strait overflow tongue. Using parameters (bottom slope, density contrast, ambient stratification) characteristic for the Denmark Strait overflow plume in the Irminger Basin we reproduce realistic eddy sizes and propagation although our model geometry is simplified. We found that a form of baroclinic instability that was discussed theoretically by Swaters (1991) is responsible for the initial destabilization of a dense filament of overflow water. We demonstrated that the observed dominance of near-surface cyclones above the lower edge of the overflow plume can be explained by the nonlinear advection of cyclonic vorticity that is wrapped into the developing cyclone at the downslope edge of the plume. The horizontal velocity shear is here higher than on the upslope edge where anticyclones are formed. In addition to that, potential vorticity conservation following fluid particles (appendix) exhibits an inherent nonlinearity that, at high Rossby numbers, favors cyclogenesis.

With the simplified model configuration we were able to produce a stable reference state. The unperturbed filament undergoes an adjustment process and evolves into a baroclinic bidirectional flow without any eddies. Therefore we were able to compare the transport characteristics for the cases with and without vortices. In the eddy case the nonlinear evolution eventually reaches saturation, and we analyzed the new mean state. It is characterized by three important features: anticyclonic eddies that are rich of original overflow water (upslope of the original core), cyclones that entrain considerable amounts of ambient water (downslope of the core), and an intensified bottom jet that is confined by the counterrotating eddies. As the self-propelling mechanism of eddies on a sloping bottom favors alongslope motion, the vortices, being a result of an instability, stabilize the outflow plume as a narrow bottom jet.

The results of this study apply not only to the Denmark Strait overflow plume but also to other outflows. In one sensitivity experiment, using a smaller density contrast and a less stratified ambient water body (not shown), we were able to produce sustainable intermediate water anticyclones that resembled Mediterranean water eddies (meddies). The processes observed in this particular case were similar to the meddy experiments of Jungclaus (1999).

Using an highly idealized model setup we have excluded effects that are associated with inflow boundaries and the initial sinking of the plume. A model experiment used with realistic topography including the Denmark Strait and the southern Iceland Basin (Käse and Oschlies 2000), showed eddies similar to those described here. However, the accelerated flow through the strait and the abrupt downslope sinking at the strait's exit were additional sources of mesoscale variability that were partly stationary and partly advected downstream. Studies such as ours and Spall and Price (1998) are therefore helpful to sort out selected processes and allow for better interpretations of more comprehensive numerical studies.

Acknowledgments. This study was funded by the Deutsche Forschungsgemeinschaft DFG, SFB 460 (J. J.) and by the European Union CANIGO project (J. H.). The comments of Lynne Talley and two anonymous reviewers were helpful in improving the manuscript and are gratefully acknowledged.

\section{APPENDIX}

\section{A Potential Vorticity Argument}

For a continuously stratified frictionless baroclinic flow, Ertel's potential vorticity is

$$
Q=-(f \mathbf{k}+\zeta) \cdot \frac{\boldsymbol{\nabla} \rho}{\rho} ;
$$

$Q$ is conserved following fluid parcels. Assuming thermal wind balance the PV can be written as (Prater and Sanford 1994):

$$
Q=-\frac{1}{\rho}(f+\zeta) \frac{\partial \rho}{\partial z}-\frac{f}{g}\left[\left(\frac{\partial u}{\partial z}\right)^{2}+\left(\frac{\partial v}{\partial z}\right)^{2}\right] .
$$

The local density is given by $\rho=\rho_{M}(z)+\rho^{\prime}(x, y$, $z$ ), where $\rho_{M}$ is the background density of the initial state outside the dense filament and $\rho^{\prime}$ is the density anomaly. Introducing background and perturbation buoyancy frequencies $N_{M}$ and $N^{\prime}$, respectively, PV can be expressed in terms of nondimensional parameters (Prater and Sanford 1994):

$$
Q=Q_{M}\left[1+\mathrm{Ro}+B+\operatorname{Ro} B-\mathrm{Ri}^{-1}\right],
$$

where $Q_{M}$ is the mean PV $f N_{M}^{2} / g$, Ro is a Rossby number $\zeta / f, B$ is the buoyancy anomaly term $N^{\prime 2} / N_{M}^{2}$, and $\mathrm{Rt}^{-1}$ is an inverse Richardson number $\left[(\partial v / \partial z)^{2}+(\partial u / \partial z)^{2}\right] /$ $N_{M}^{2}$. The background PV is modified by changes in the vertical stratification, by the relative vorticity, and the vertical shear of the horizontal velocities. Note the nonlinear term $\operatorname{Ro} B$ that reflects combined effects of horizontal velocity shear and vertical density variations. Assuming potential vorticity conservation between a time $t=0$ and $t=\Delta t$ the change in the relative vorticity term ( $f$ is constant here) Ro can be expressed as

$$
\Delta \mathrm{Ro}=\frac{-\Delta B\left(1+\mathrm{Ro}_{0}\right)-\Delta \mathrm{Ri}^{-1}}{\left(1+B_{0}+\Delta B\right)} .
$$

Here an index 0 marks the variable at $t=0$ and $\Delta$ indicates the difference of the respective variable between $t=0$ and $t=\Delta t$. Assume, as a first step, that the inverse Richardson number is small (i.e., the vertical velocity shear is small, a condition fulfilled in the model outside the dense bottom flow). We find Krauss and 

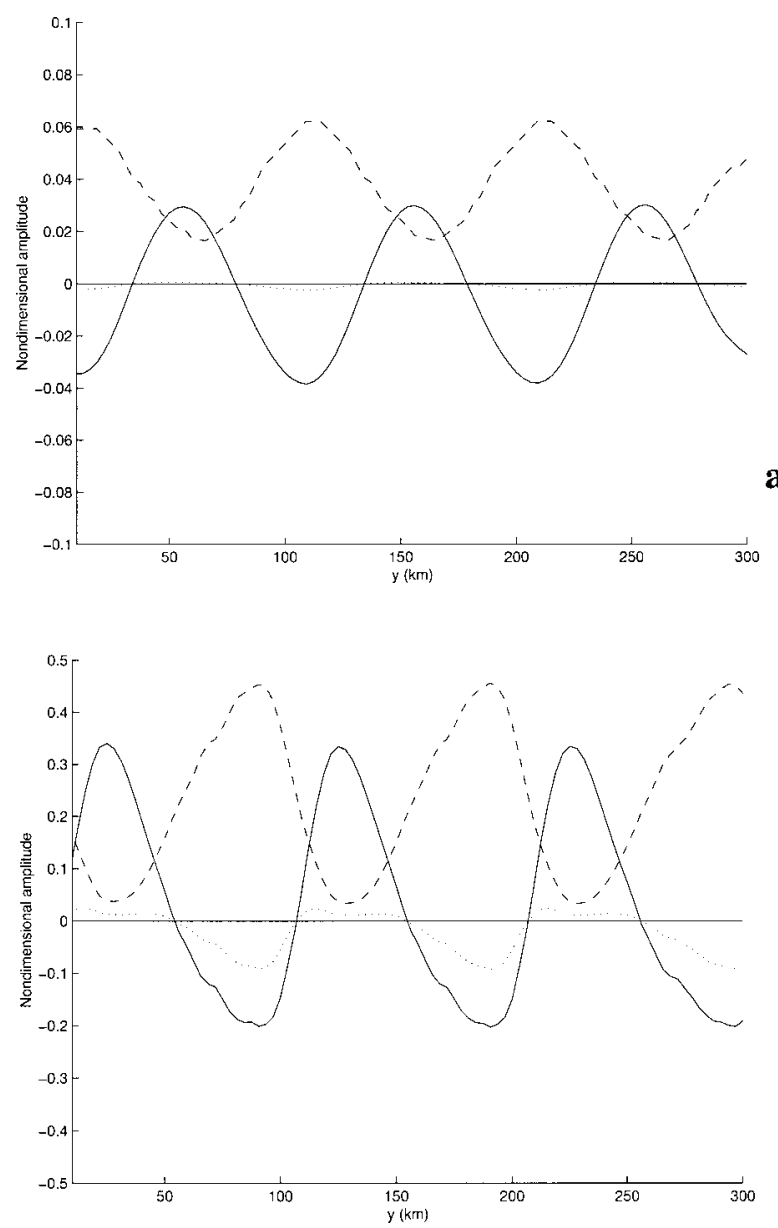

FIG. A1. The nondimensional terms Rossby number Ro (solid line), buoyancy anomaly (dashed line), and nonlinear term $B$ Ro (dotted line) contributing to the modification of potential vorticity calculated on the isopycnal $\sigma=27.66 \mathrm{~kg} \mathrm{~m}^{-3}$ at $x=100 \mathrm{~km}$ from (a) the smallperturbation experiment (expt 4) and (b) the standard experiment (expt 2).

Käse's (1998) PV conservation argument if we consider a decrease in $B$ (corresponding to an increase in $H$ in their formulation). The relative change $\Delta$ Ro will be smaller if $\mathrm{Ro}_{0}$ is negative compared to an initially positive $\mathrm{Ro}_{0}$. For example, $B=1 ; \Delta B=-0.1$; then for $\mathrm{Ro}_{0}=+(-) 0.5 \Delta \mathrm{Ro}=0.079(-0.026)$, respectively. Or, in another way of looking at it, we start the clock at a time where the relative vorticity just changes sign (i.e., $\mathrm{Ro}_{0}=0$ at $t=0$ ) so that we have $\Delta \mathrm{Ro}=-\Delta B$ / $\left(1+B_{0}+\Delta B\right)$. Now the effect of the nonlinearity is that increasing the buoyancy anomaly induces a slightly smaller change in the Rossby number than decreasing it. Take, for example, $B_{0}=1, \Delta B=+(-) 0.1$. Then $\Delta \mathrm{Ro}=-0.047(0.053)$, respectively. It appears that the nonlinear term $B$ Ro favors cyclonic eddies.

We calculated the terms of Eq. (A4) using modeled variables. In Fig. A1 the buoyancy anomaly, the Rossby number, and the nonlinear term calculated on the isopycnal $\sigma=27.66$ at $x=100 \mathrm{~km}$ are displayed for the linear small-perturbation case (expt 4, Fig. A1a) and the standard case (expt 2, Fig. A1b). The curves show the expected out of phase relation between buoyancy anomaly stretching (squeezing) and cyclonic (anticyclonic) relative vorticity. When both Ro and $B$ are small (Fig. A1a) the nonlinear term is negligible and Ro is symmetric in terms of cyclonic (anticyclonic) relative vorticity. In the nonsymmetric experiment (Fig. A1b) the nonlinear term is relatively large when the buoyancy anomaly is strongly positive. Here the $B$ Ro term is up to $50 \%$ of the Ro term and contributes significantly to the balance of terms. When $B$ is small, $B$ Ro is also small and the Ro term has to be considerably larger to maintain the balance. In the model calculations the nonlinear term in (A4) is of particular importance where horizontal velocity shear coincides with variations in the stratification. In the beginning of the experiment this is the case mostly at the lower edge of the flow where there is pronounced cyclonic vorticity. Here the amplifying cyclone wraps the edge water with its already high positive vorticity around its center (cf. Fig. 10).

\section{REFERENCES}

Armi, L., and W. Zenk, 1984: Large lenses of highly saline Mediterranean water. J. Phys. Oceanogr., 14, 1560-1576.

Blumberg, A. F., and G. L. Mellor, 1987: A description of a threedimensional coastal ocean circulation model. Three-Dimensional Coastal Ocean Models, N. Heaps, Ed., Coastal and Estuarine Series, Vol. 4, Amer. Geophys. Union, 208 pp.

Bruce, J. G., 1995: Eddies southwest of Denmark Strait. Deep-Sea Res., 42, 13-29.

Bush, A. B. G., J. C. McWilliams, and W. R. Peltier, 1995: The formation of oceanic eddies in symmetric and asymmetric jets. Part I: Early time evolution and bulk eddy transports. J. Phys. Oceanogr., 25, 1959-1979.

Cooper, L. H. N., 1955: Deep water movements in the North Atlantic as a link between climatic changes around Iceland and biological productivity of the English Channel and Celtic Sea. J. Mar. Res., 14, 347-362.

Ezer, T., and G. Weatherly, 1990: A numerical study of the interaction between a deep cold jet and the bottom boundary layer of the ocean. J. Phys. Oceanogr., 20, 801-816.

Gill, A. E., 1982: Atmosphere-Ocean Dynamics. Academic Press, $662 \mathrm{pp}$.

Griffiths, R. W., P. D. Killlworth, and M. E. Stern, 1982: A geostrophic instabilities of ocean currents. J. Fluid Mech., 117, 343-377.

Jiang, L., and R. W. Garwood, 1996: Three-dimensional simulations of overflows on continental slopes. J. Phys. Oceanogr., 26, $1214-1233$.

Jungclaus, J. H., 1999: A three-dimensional simulation of the formation of anticyclonic lenses (meddies) by the instability of an intermediate depth boundary current. J. Phys. Oceanogr., 29, $1579-1598$.

_ , and J. O. Backhaus, 1994: Application of a transient reduced gravity plume model to the Denmark Strait overflow. J. Geophys. Res., 99, 12 375-12 396.

— the Mediterranean outflow. J. Mar. Syst., 24, 41-66.

Karsten, R. H., G. E. Swaters, and R. E. Thomson, 1995: Stability characteristics of deep-water replacement in the Strait of Georgia. J. Phys. Oceanogr., 25, 2391-2403.

Käse, R. H., and A. Oschlies, 2000: Flow through Denmark Strait. J. Geophys. Res., 105, 28 527-28 546. 
Killworth, P. D., 1977: Mixing on the Weddell Sea continental slope. Deep-Sea Res., 24, 427-448.

Krauss, W., 1996: A note on overflow eddies. Deep-Sea Res., 43, 1661-1667.

— , and R. H. Käse, 1998: Eddy formation in the Denmark Strait overflow. J. Geophys. Res., 103, 15 525-15 538.

Mellor, G. L., and T. Yamada, 1982: Development of a turbulence closure model for geophysical fluid problems. Rev. Geophys. Space Phys., 20, 851-875.

_ , and A. F. Blumberg, 1985: Modeling vertical and horizontal diffusivities with the sigma-coordinate system. Mon. Wea. Rev., 113, 1380-1383.

Nof, D., 1983: The translation of isolated eddies on a sloping bottom. Deep-Sea Res., 30, 171-182.

Prater, M. D., and T. B. Sanford, 1994: A meddy off Cape St. Vincent. Part I: Description. J. Phys. Oceanogr., 24, 1572-1586.

Price, J. F., and M. O. Baringer, 1994: Outflow and deep water production by marginal seas. Progress in Oceanography, Vol. 33, Pergamon, 161-200.
Qui, B., N. Imasoto, and T. Awaji, 1988: Baroclinic instability of buoyancy-driven coastal density currents. J. Geophys. Res., 93, 5037-5050.

Smith, P. C., 1975: A streamtube model for bottom boundary currents in the ocean. Deep-Sea Res., 22, 853-873.

_ 1976 : Baroclinic instability in the Denmark Strait overflow. J. Phys. Oceanogr., 6, 355-371.

Snyder, C., W. C. Skamarock, and R. Rotunno, 1991: A comparison of primitive equation and semigeostrophic simulations of baroclinic waves. J. Atmos. Sci., 48, 2179-2194.

Spall, M. A., and J. F. Price, 1998: Mesoscale variability in Denmark Strait: The PV outflow hypothesis. J. Phys. Oceanogr., 28, 15981623 .

Swaters, G. E., 1991: On the baroclinic instability of cold-core coupled density fronts on a sloping continental shelf. J. Fluid Mech., 224, 361-382.

Worthington, L. V., 1969: An attempt to measure the volume transport of Norwegian Sea overflow water through the Denmark Strait. Deep-Sea Res., 16, 421-432. 